\title{
Wing shape as a taxonomic trait: separating genetic variation from host-induced plasticity in aphid parasitoids
}

\author{
MARÍA ALEJANDRA PARREÑO ${ }^{1,2,3 *}$, ANA IVANOVIĆ ${ }^{4}$, ANDJELJKO PETROVIĆ ${ }^{4}$, \\ VLADIMIR ŽIKIĆ́ ${ }^{5}$, ŽELJKO TOMANOVIĆ ${ }^{4}$ and CHRISTOPH VORBURGER ${ }^{1,6}$
}

${ }^{1}$ EAWAG, Swiss Federal Institute of Aquatic Science and Technology, Überlandstrasse 133, 8600

Dübendorf, Switzerland

${ }^{2}$ Department of Ecology and Evolution, University of Lausanne, Le Biophore, 1015 Lausanne,

Switzerland

${ }^{3}$ Department of Evolutionary Biology and Environmental Studies, University of Zurich, Winterthurerstrasse 190, 8057 Zurich, Switzerland

${ }^{4}$ Institute of Zoology, Faculty of Biology, University of Belgrade, Studentski trg 16, 11000 Belgrade, Serbia

${ }^{5}$ Department of Biology and Ecology, Faculty of Sciences and Mathematics, University of Niř, Višegradska 33, 18000 Niš, Serbia

${ }^{6}$ Institute of Integrative Biology, ETH Zürich, Universitätstrasse 16, 8092 Zürich, Switzerland

Received 31 July 2015; revised 21 July 2016; accepted for publication 22 July 2016

\begin{abstract}
Separating environmental effects on an organism's phenotype from genetic effects is not only of evolutionary interest, but also important in morphological taxonomy. Ideally, morphological traits to distinguish species are robust to environmental variation. In taxonomically difficult groups of insects such as aphid parasitoids (Hymenoptera: Braconidae: Aphidiinae), wing shape quantified by geometric morphometrics is increasingly used to distinguish cryptic species that are difficult to separate with other morphological characters. However, aphid parasitoids may use multiple host species; the validity of this approach thus hinges on wing shape being a genetically hard-wired trait that is not strongly moulded by the host in which the parasitoid develops. The occurrence of asexual lines in the aphid parasitoid Lysiphlebus fabarum (Marshall) provides an opportunity to test this assumption by rearing genetically identical individuals in different environments. We reared five asexual lines of $L$. fabarum in four different aphid species to quantify the relative importance of these factors on parasitoid wing shape. We found that the parasitoid genotype explains a much larger proportion of the observed variation in wing shape than the host species. The host also significantly affected wing shape, but to a lesser extent, and largely via an effect on size (allometry), which can be corrected for. Our study shows that even at the level of lineages within a single species, the influence of the host environment is small relative to the genetic determination of wing shape, thus validating the use of this trait for taxonomic purposes.
\end{abstract}

(C) 2016 The Linnean Society of London, Zoological Journal of the Linnean Society, 2017 doi: 10.1111/zoj.12490

ADDITIONAL KEYWORDS: allometry - geometric morphometrics - phenotypic plasticity - taxonomy.

\section{INTRODUCTION}

An organism's phenotype is determined by its genotype and the environment in which it develops.

*Corresponding author. E-mail: alejandra.parreno@ieu.uzh.ch
Quantifying these influences and potential interactions between them is an important goal of evolutionary biology, because this information is required for predicting evolutionary responses to phenotypic selection (Grant \& Grant, 1995). Separating environmental effects on the phenotype from genetic effects is also important in taxonomy. Ideally, morphological 
traits to distinguish species are genetically hardwired and show little phenotypic plasticity. In insects there are numerous cases of different, environmentally induced morphs that were erroneously treated as different species until more detailed studies of life-cycles or molecular analyses identified them as conspecific (Nijhout, 1999).

Parasitoids may constitute up to $25 \%$ of all insects (Godfray, 1994) and have proven to be particularly challenging for taxonomic treatment. The parasitoid lifestyle has evolved in several insect clades, of which the Tachinidae (Diptera), Ichneumonoidea (Hymenoptera), and Chalcidoidea (Hymenoptera) are probably the best known. All of them are extremely species-rich, yet the true species diversity is still strongly underestimated because many insect parasitoids have radiated into numerous host-specialized species with very similar morphologies. This has been demonstrated impressively by a series of DNA barcoding studies on tropical parasitoids, in which morphologically described species that were presumed to be generalists were found to consist of numerous cryptic species with very narrow host ranges (Smith et al., 2006, 2007, 2008).

An interesting case in point is provided by endoparasitoids of aphids from the subfamily Aphidiinae (Hymenoptera: Ichneumonoidea: Braconidae). A number of new species has been described over recent years that have distinct host ranges but are morphologically very similar to related species (e.g. Petrović et al., 2011; Rakhshani et al., 2011; Kos et al., 2012). In some cases, comparisons of parasitoid wing shape using geometric morphometrics have indicated that the overall shape of the wing can separate species that are difficult to distinguish with traditionally used characters (Mitrovski-Bogdanović et al., 2013, 2014). In addition, wing venation patterns provide important diagnostic characters for many aphidiine genera (Starý, 1970). This suggests that the geometric morphometric analysis of wing shape may be a useful additional tool for the taxonomy of aphid parasitoids. However, different cryptic species tend to be specialized on different aphid hosts, and wing shape differences may also arise from developing in different host environments. The utility for taxonomy thus hinges on wing shape being a rigid, genetically determined trait that is not strongly moulded by the environment that the parasitoid develops in. Otherwise this character could be misleading in more generalist species that use multiple hosts. That wing shape fulfils this requirement is an untested assumption.

Aphid parasitoids of the Lysiphlebus fabarum (Marshall) group provide an excellent opportunity to test this assumption. These parasitoids are important natural enemies of aphids, mostly from the genera Aphis and Brachycaudus (Starý, 2006).
Exceptionally amongst aphid parasitoids, the predominant mode of reproduction in these wasps is parthenogenesis via thelytoky, i.e. females produce daughters from unfertilized diploid eggs (Starý, 1988; Belshaw et al., 1999). Thelytoky in L. fabarum is genetically determined and occurs via central fusion automixis (Belshaw \& Quicke, 2003; Sandrock \& Vorburger, 2011), such that thelytokous lines are highly homozygous and genetically homogeneous, virtually like clones. This allows rearing of the same parasitoid genotypes in multiple aphid hosts to estimate the environmental influence on wing shape. Presumably because of the prevalent occurrence of thelytoky, the $L$. fabarum group is one of the most taxonomically difficult clades of aphid parasitoids (Sandrock, Schirrmeister \& Vorburger, 2011), and recent research suggests that wing shape may be used to distinguish otherwise cryptic taxa within this group (Petrović et al., 2015). However, it remains unclear whether these differences come about by using different aphid host species or whether they reflect genetic differences in wing shape amongst lineages. We addressed this issue by rearing five different asexual lines of the aphid parasitoid $L$. fabarum on four different host species in a crossed factorial design. This allowed us to quantify the relative contributions of genotype and host environment on wing shape to test whether wing shape is stable enough across different hosts to serve as a taxonomically useful trait.

\section{MATERIAL AND METHODS}

\section{INSECT LINES}

Five thelytokous lines of $L$. fabarum were used in this study. For simplicity, they are referred to as L1-L5. Information on the site, date, and aphid host species from which they were originally collected is provided in Table 1. Each line was founded from a single female and since then reared in Aphis fabae (Scopoli) on broad bean plants (Vicia faba L.) under optimal conditions in a climate-controlled room $\left(20^{\circ} \mathrm{C}, 16 \mathrm{~h}\right.$ photoperiod). The five all-female lines are distinguishable by microsatellites analysis (Sandrock et al., 2007), and some lines have been used under different names (for lab IDs see Table 1) in earlier studies (e.g. Vorburger et al., 2009; Rouchet \& Vorburger, 2012; C. Vorburger \& R. Rouchet, unpubl. data). L5 is the only line that is morphologically distinguishable by eye because, in contrast to the other four lines, it carries a fringe of long setae on the margin of the forewing. Based on this trait it would be named Lysiphlebus confusus according to traditional taxonomy (Tremblay \& Eady, 1978), but more recent work has indicated that it represents a morphotype within the $L$. fabarum group (Sandrock et al., 2011). 
Table 1. Collection details of five thelytokous lines of the aphid parasitoid Lysiphlebus fabarum used in this study

\begin{tabular}{lllll}
\hline Line no. & Lab ID & Collection site & Collection date & Collected from (host) \\
\hline L1 & $07-59$ & Zurich, Switzerland & $25 / 09 / 2007$ & Aphis hederae \\
L2 & $07-64$ & Wildberg, Switzerland & $16 / 09 / 2007$ & Aphis fabae fabae \\
L3 & $09-402$ & Langenthal, Switzerland & $03 / 07 / 2009$ & Aphis fabae cirsiiacanthoides \\
L4 & $06-533$ & Langenselbold, Germany & $02 / 07 / 2006$ & Aphis fabae cirsiiacanthoides \\
L5 & $09-554$ & Aesch, Switzerland & $24 / 06 / 2009$ & Aphis ruborum \\
\hline
\end{tabular}

As aphid hosts we used one clonal line from each of four species of the genus Aphis: A. fabae, Aphis hederae (Kaltenbach), Aphis gossypii (Glover), and Aphis urticata (Gmelin). The laboratory line of A. fabae was initiated in 2006 whereas the other aphid lines were initiated in 2013, all from single females collected in Switzerland. Aphis fabae was maintained on broad beans, A. hederae on ivy (Hedera helix L.), A. gossypii on cucumbers (Cucumis sativa L.), and A. urticata on stinging nettles (Urtica dioica L.), under conditions ensuring continuous parthenogenetic reproduction $\left(20^{\circ} \mathrm{C}, 16 \mathrm{~h}\right.$ photoperiod). All aphid clones were tested for the presence of the facultative bacterial endosymbiont Hamiltonella defensa (Moran et al., 2005), using diagnostic PCR with the primers of Ferrari et al. (2012). Hamiltonella defensa is a defensive symbiont that strongly increases aphid resistance to parasitoids (Oliver et al., 2003; Vorburger et al., 2009). All aphids were uninfected with $H$. defensa and therefore suitable for parasitoid rearing.

To obtain the individuals for wing shape analysis, the four aphid species were exposed to parasitoids of the five thelytokous lines in all possible combinations by caging female wasps in cellophane bags on potted plants infested with aphid nymphs. Successfully infected aphids turned into characteristic 'mummies' within 8-9 days. When the adult wasps emerged from these mummies (approx. 14 days after infection) they were collected and stored in $70 \%$ ethanol until used for morphometrics. The goal was to obtain 30 wasps from each aphid species-parasitoid line combination. As not all parasitoid lines developed equally well on all aphid species, this required several repetitions for some combinations and even failed in a few cases. The final sample sizes that we obtained are provided in Table 2. The inability to obtain 30 wasps from all combinations resulted in a factorial design that was not fully balanced. Therefore, we analysed a reduced but fully balanced data set (L1, L3, L4, and L5 from A. fabae, A. gossypii, and A. hederae) in addition to the complete data set, but as the results were very similar, we only report the results from the complete data set here.
Table 2. Sample sizes obtained for morphometric analyses of wing shape of five thelytokous lines of Lysiphlebus fabarum reared on four different aphid species

\begin{tabular}{lllll}
\hline \multirow{5}{*}{$\begin{array}{l}\text { Aphid species } \\
\text { Parasitoid }\end{array}$} & $\begin{array}{l}\text { Aphis } \\
\text { line }\end{array}$ & $\begin{array}{l}\text { Aphis } \\
\text { fabsesypii }\end{array}$ & $\begin{array}{l}\text { Aphis } \\
\text { hederae }\end{array}$ & $\begin{array}{l}\text { Aphis } \\
\text { urticata }\end{array}$ \\
\hline L1 & 30 & 30 & 30 & 0 \\
L2 & 30 & 30 & 5 & 9 \\
L3 & 30 & 30 & 30 & 3 \\
L4 & 30 & 30 & 30 & 15 \\
L5 & 30 & 30 & 30 & 3 \\
\hline
\end{tabular}

\section{WING IMAGES AND LANDMARKS}

From all adult parasitoids obtained, the right forewing was removed and mounted on microscope slides using Swan's mounting medium (Swan, 1936), following the procedure described by MitrovskiBogdanović et al. (2013). Photographs were taken with a Leica DFC290 digital camera mounted on a Leica M205C microscope at a constant magnification and light intensity. On these pictures, 13 landmarks were placed and digitized into coordinates using TpsDig2 v. 2.12 software (Rohlf, 2009; Fig. 1). Landmarks were chosen based on previous studies on the species so that they cover the distal and proximal parts of the wing, wing edges, and vein projections (Petrović et al., 2015). Landmarks 4, 5, 11, and 12 define the stigma and metacarpus. Landmarks 5, 6 , and 13 define the radial vein. The general outline of the wing is denoted by landmarks $3,8,9,10,11$, and 12 , of which 8,9 , and 10 are projections of the three veins on the wing edge.

\section{MORPHOMETRIC ANALYSES}

The landmark configurations were analysed using MorphoJ software (Klingenberg, 2011) A generalized Procrustes analysis was performed to remove variation in scale, position, and orientation of wings and obtain the matrix of shape variables (Procrustes coordinates). A principal component analysis (PCA) 


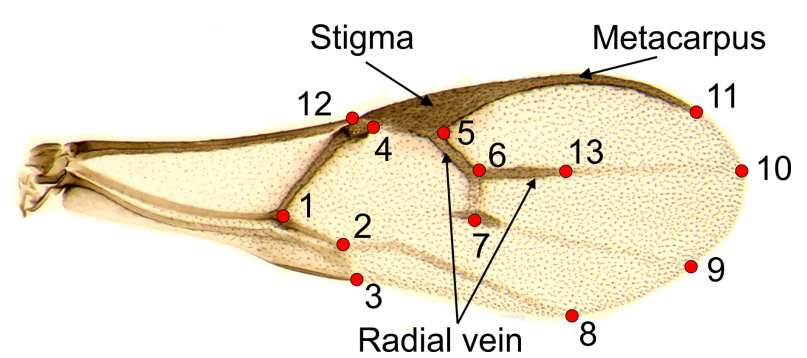

Figure 1. Lysiphlebus fabarum right forewing with 13 selected landmarks. Terminology of Sharkey \& Wharton (1997) was used.

was conducted on the Procrustes coordinates to explore variation in wing shape and visualize shape changes associated with the principal components. Mean shapes per group and Procrustes distances between mean shapes of genetic lines or hosts were calculated. The statistical significance of differences between group means was determined using a permutation test with 10000 iterations.

To estimate the relative contributions of parasitoid genotype and aphid host on wing shape variation, we used the statistical software $R$ ( $R$ Core Team, 2015) to run a two-way multivariate analysis of variance (MANOVA) (type III) on the principal component (PC) scores from the first ten PCs that together captured most of the variation $(90 \%)$. We then used Wilk's partial eta-squared $\left(\eta^{2}\right)$ as an estimate of partial variance explained to compare effect sizes (Langerhans \& DeWitt, 2004).

As aphid species differ somewhat in size, at least part of any host-induced changes in parasitoid wing shape may simply reflect size differences of parasitoids emerging from them owing to size-related, allometric shape changes. We thus used MorphoJ to calculate centroid size (CS) as a measure of overall wing size and to apply multivariate regression of Procrustes coordinates on natural log-transformed centroid size (lnCS) to estimate size-related changes in wing shape and to obtain residuals representing non-allometric shape components (Klingenberg, 1998; Monteiro, 1999). We then repeated all analyses with allometry-free shape variables for comparison. Wing size (lnCS) was compared amongst parasitoid lines and aphid hosts with a two-way analysis of variance using $\mathrm{R}$. We analysed $\operatorname{lnCS}$ rather than CS to improve homogeneity of variances as the variance scaled with the mean in our data.

\section{RESULTS}

\section{WING SIZE VARIATION}

Wing size analysed as lnCS differed significantly amongst parasitoid lines $\left(F_{4,436}=15.36, P<0.001\right)$, with line explaining $12 \%$ of the variation. The aphid host in which parasitoids developed had the strongest effect on wing size $\left(F_{3,436}=278.66, P<0.001\right)$, explaining $52 \%$ of the variation. Average wing sizes were largest when parasitoids developed in A. fabae (mean $\mathrm{CS}=1318.7 \pm 113.5 \quad \mathrm{SD})$, followed by A. hederae (mean $\mathrm{CS}=1104.4 \pm 116.4 \quad \mathrm{SD}$ ), A. gossypii (mean $\mathrm{CS}=1061.4 \pm 86.6 \quad \mathrm{SD}$ ), and A. urticata (mean CS $=1013.0 \pm 87.6 \mathrm{SD}$ ). A significant parasitoid line $\times$ aphid species interaction indicated that the effect of the aphid host on wasp wing size was not equal for all parasitoid genotypes $\left(F_{11,436}=8.79, \quad P<0.001\right)$, but the interaction explained only $6 \%$ of the variation in $\operatorname{lnCS}$.

\section{WING SHAPE VARIATION}

A PCA on the Procrustes coordinates yielded a first PC (PC1) that explained $26.0 \%$ of the variation in wing shape; PC2 and PC3 explained 18.1 and $11.8 \%$, respectively. The first ten PCs combined explained $90.4 \%$ of the variation in wing shape. Figure 2 shows bivariate plots with the first two PCs. PC1 orders wings along an axis from shorter wings with a wide and blunt distal part to longer wings with a narrow and pointed distal part, and PC2 orders wings along an axis from wider wings with a short metacarpus and a short radial vein to narrower wings with a long metacarpus and an elongated radial vein. The different wasp lines are quite well separated in the plane described by these two axes (Fig. 2), except for a strong overlap between L3 and L4, which are however separated clearly in the morphospace described by PC3 and PC4 (data not shown), and a partial overlap between L1 and L5. Thus, the five parasitoid lines exhibit genetic differences in wing shape. The same plot grouped by host shows strong overlap of wing shapes in wasps that had developed in different aphid species (Fig. 2). That the wasps' genotype had a stronger effect on wing shape than the aphid species in which they developed was also supported by the pairwise Procrustes distances between groups (Table 3). All comparisons were statistically significant, but the Procrustes distances were larger on average between parasitoid lines than between host species. The relative importance of these effects was quantified with a factorial MANOVA on the scores of the first ten PCs as a concise description of shape. Although both main effects and their interaction were highly significant, the strongest effect was that of parasitoid line, with a partial eta-squared of 0.543 (Table 4), considerably stronger than the effect of aphid species $(0.312)$ or that of the interaction (0.091).

Natural log-transformed wing size (lnCS) had a significant effect on Procrustes coordinates in a 

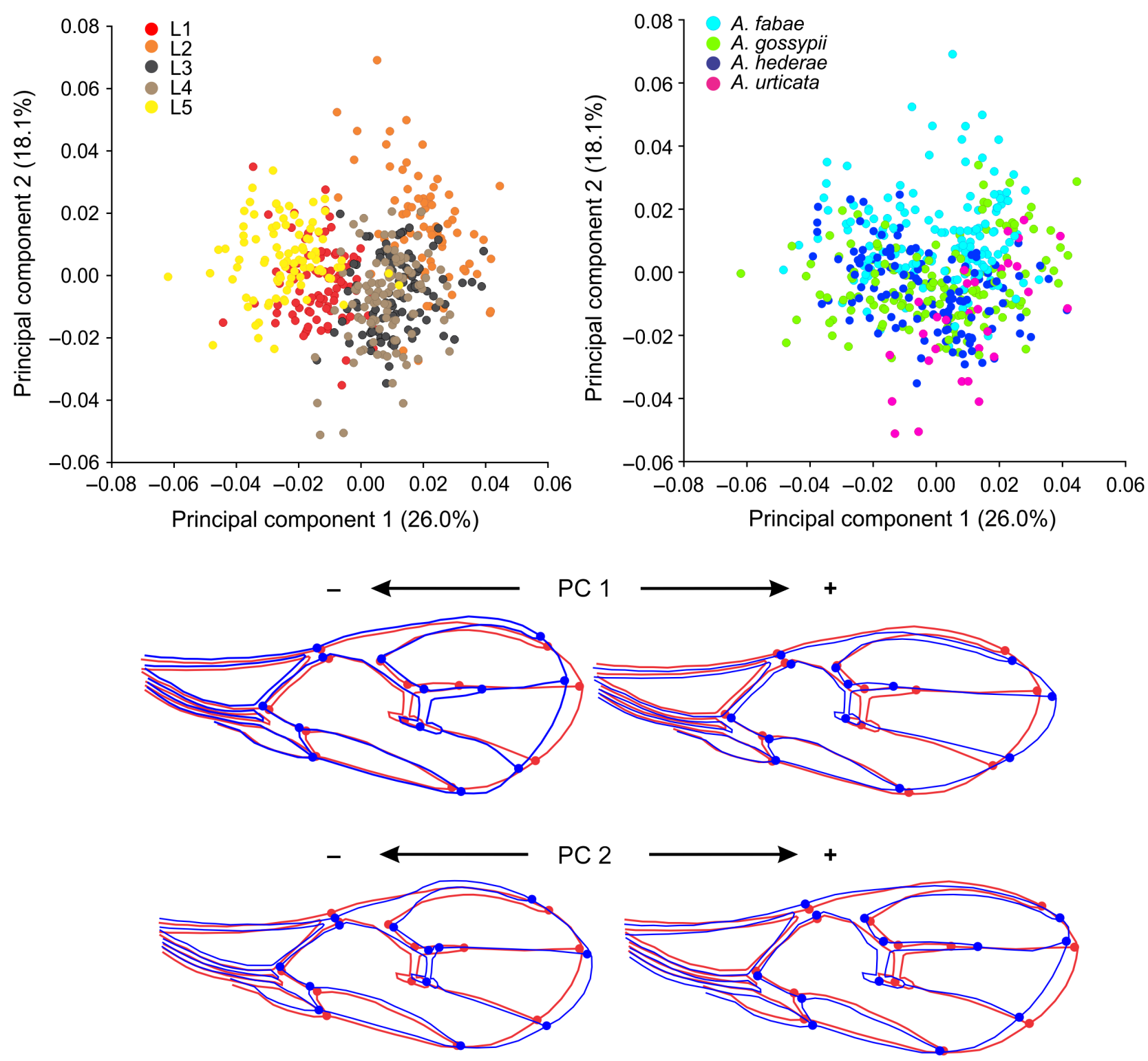

Figure 2. Positions of Lysiphlebus fabarum individuals relative to the first and second principal component (PC1 and 2) axes derived from the covariance matrix of wing shape variables (Procrustes coordinates). Individuals are colourcoded by line (L1, L2, L3, L4, L5) and by host (Aphis fabae, Aphis hederae, Aphis gossypii, and Aphis urticata). Shape changes associated with the first (PC1) and second axis (PC2) are visualized as warped outline drawings. The mean wing shape is in red and the extreme wing shapes representing the positive and negative end of each axis are in dark blue. The shape changes from the mean shape are enlarged two times.

multivariate regression $(P<0.001)$ and explained $9.4 \%$ of the variation in wing shape. Thus, part of the host effect on parasitoid wing shape was explicable by the differences in average size of parasitoids emerging from the four aphid species. This was evident from the PCA on allometry-corrected shape variables: The five parasitoid genotypes remained largely separated in a bivariate plot of the first two PCs (Fig. 3), but the same plot grouped by aphid species showed even more overlap than prior to allometry correction (compare Figs 2 and 3). Accordingly, the effect size of aphid species in a MANOVA on the scores from the first ten PCs was approximately halved after allometry correction, whereas the other effect sizes remained nearly unchanged (Table 4). When allometry was accounted for, the effect of parasitoid genotype on wing shape was 3.5fold stronger than the effect of aphid species (Table 4). The same pattern was seen when Procrustes distances between groups were recalculated 
Table 3. Differences in wing shape expressed as Procrustes distances between parasitoid lines averaged over host species (left) and between parasitoids emerging from different host species averaged over lines (right), before (A) and after (B) allometry correction

\begin{tabular}{|c|c|c|c|c|c|c|c|c|}
\hline & \multicolumn{4}{|c|}{ Between parasitoid lines } & \multicolumn{4}{|c|}{ Between aphid species } \\
\hline & L1 & $\mathrm{L} 2$ & L3 & $\mathrm{L} 4$ & & $\begin{array}{l}\text { Aphis } \\
\text { fabae }\end{array}$ & $\begin{array}{l}\text { Aphis } \\
\text { gossypii }\end{array}$ & $\begin{array}{l}\text { Aphis } \\
\text { hederae }\end{array}$ \\
\hline \multicolumn{9}{|c|}{ A) Procrustes distances prior to allometry correction } \\
\hline $\mathrm{L} 2$ & $0.0417 * * *$ & & & & A. gossypii & $0.0197 * * *$ & & \\
\hline L3 & $0.0312^{* * *}$ & $0.0271 * * *$ & & & A. hederae & $0.0199 * * *$ & $0.0088 * *$ & \\
\hline $\mathrm{L} 4$ & $0.0315^{* * *}$ & $0.0340 * * *$ & $0.0251 * * *$ & & Aphis urticata & $0.0328 * * *$ & $0.0198 * * *$ & $0.0205^{* * *}$ \\
\hline L5 & $0.0282^{* * *}$ & $0.0477 * * *$ & $0.0399 * * *$ & $0.0394 * * *$ & & & & \\
\hline \multicolumn{9}{|c|}{ B) Allometry-corrected Procrustes distances } \\
\hline $\mathrm{L} 2$ & $0.0396 * * *$ & & & & A. gossypii & $0.0089 * * *$ & & \\
\hline L3 & $0.0312^{* * *}$ & $0.0251 * * *$ & & & A. hederae & $0.0093^{* * *}$ & $0.0094 * * *$ & \\
\hline $\mathrm{L} 4$ & $0.0306^{* * *}$ & $0.0344 * * *$ & $0.0252 * * *$ & & A. urticata & $0.0258^{* * *}$ & $0.0196 * * *$ & $0.0208^{* * *}$ \\
\hline L5 & $0.0284 * * *$ & $0.0477 * * *$ & $0.0395 * * *$ & $0.0387 * * *$ & & & & \\
\hline
\end{tabular}

from allometry-corrected shape variables (Table 3). Most values remained very similar, but the Procrustes distances between wasps from $A$. fabae (which had the largest wings by far) and wasps developing in the other three hosts became substantially smaller. A visual representation of the differences in mean wing shape between parasitoid lines is provided in Figure 4.

Although it explained only a small proportion of the variation in wing shape described by the first ten PCs, the parasitoid line $\times$ aphid species interaction was statistically significant before as well as after allometry correction (Table 4). As our main interest was in the general robustness of wing shape across host environments rather than in any specific differences amongst particular wasp genotypes or particular host aphids, we did not illustrate all possible pairwise comparisons. However, we calculated pairwise Procrustes distances between wasps from the different hosts separately for each line and between lines for each of the different hosts (Table S1, Supporting Information). These results confirmed that wing shape differences within lines resulting from development in different hosts were substantially smaller on average than differences amongst lines, even when the two morphologically most similar lines L3 and L4 were considered (Table S1, Supporting Information).

\section{DISCUSSION}

We have shown that different asexual lines of the aphid parasitoid $L$. fabarum exhibit genetic variation in wing shape that remains detectable when parasitoids are reared in different aphid species. The
Table 4. Multivariate analysis of variance (type III) results for the scores from the first ten principal components of a principal component analysis on Procrustes coordinates (A) and allometry-corrected shape variables (B) of Lysiphlebus fabarum wings

\begin{tabular}{|c|c|c|c|c|}
\hline Effect & Wilk's $\lambda$ & $\begin{array}{l}\text { Approx. } \\
F\end{array}$ & $P$ & $\begin{array}{l}\eta^{2} \text { (partial } \\
\text { variance } \\
\text { explained) }\end{array}$ \\
\hline \multicolumn{5}{|c|}{ A) Without allometry correction } \\
\hline $\begin{array}{l}\text { Parasitoid } \\
\text { line }\end{array}$ & 0.044 & 52.077 & $<0.001$ & 0.543 \\
\hline $\begin{array}{l}\text { Aphid } \\
\text { species }\end{array}$ & 0.326 & 19.452 & $<0.001$ & 0.312 \\
\hline Interaction & 0.385 & 3.967 & $<0.001$ & 0.091 \\
\hline \multicolumn{5}{|c|}{ B) Allometry-corrected } \\
\hline $\begin{array}{l}\text { Parasitoid } \\
\text { line }\end{array}$ & 0.044 & 51.610 & $<0.001$ & 0.541 \\
\hline $\begin{array}{l}\text { Aphid } \\
\text { species }\end{array}$ & 0.603 & 7.853 & $<0.001$ & 0.155 \\
\hline Interaction & 0.365 & 4.203 & $<0.001$ & 0.096 \\
\hline
\end{tabular}

aphid host influenced parasitoid wing shape as well (31\% of partial variance explained compared with $54 \%$ explained by genotype), although the host effect occurred to a large extent via allometric changes related to size. When allometry was accounted for, aphid species explained only $15 \%$ of the partial variation in wing shape. Overall, our results show that wing shape is genetically determined and relatively invariant across different host environments, which is an important requirement for its use in the taxonomy of aphid parasitoids. 

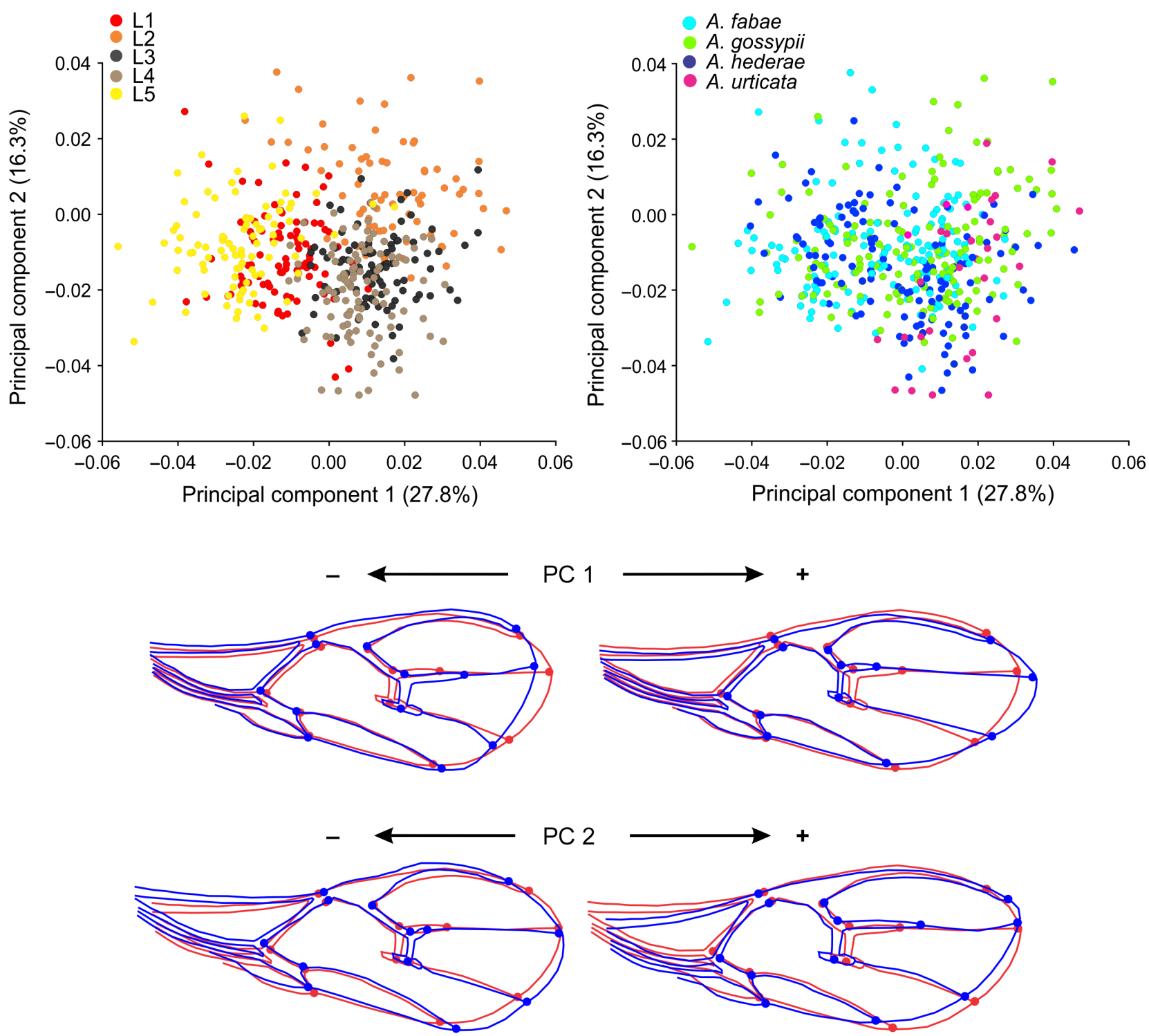

Figure 3. Positions of Lysiphlebus fabarum individuals relative to the first and second principal component (PC1 and 2) axes derived from the covariance matrix of allometry-corrected wing shape variables (residuals from multivariate regression of Procrustes coordinates on natural log-transformed centroid size). Individuals are colour-coded by lines (L1, L2, L3, L4, L5) and by host (Aphis fabae, Aphis hederae, Aphis gossypii, and Aphis urticata). Shape changes associated with the first (PC1) and second axis (PC2) are visualized as warped outline drawings. The mean wing shape is in red and the extreme wing shapes representing the positive and negative end of each axis are in dark blue. The shape changes from the mean shape are enlarged two times.

There is also evidence from Drosophila melanogaster that wing shape is remarkably robust to environmental perturbations (Birdsall et al., 2000). However, this does not imply that wing shape is generally useful as a taxonomic trait. It is an empirical observation that in aphid parasitoids, wing shape often differs significantly amongst otherwise cryptic species that are distinguishable by molecular methods (Mitrovski-Bogdanović et al., 2013, 2014; Petrović et al., 2015; Stanković et al., 2015). As such species often exploit different hosts, it is useful to know that even in different genotypes of the same species, wing shape is a relatively rigid, genetically determined trait that does not simply reflect a plastic response to the aphid in which the parasitoid developed. It also helps to interpret earlier findings of wing shape variation in cryptic taxa of aphid parasitoids (e.g. Žikić et al., 2009). The utility of wing shape as a taxonomic trait in other groups of insects would have to be established independently because 

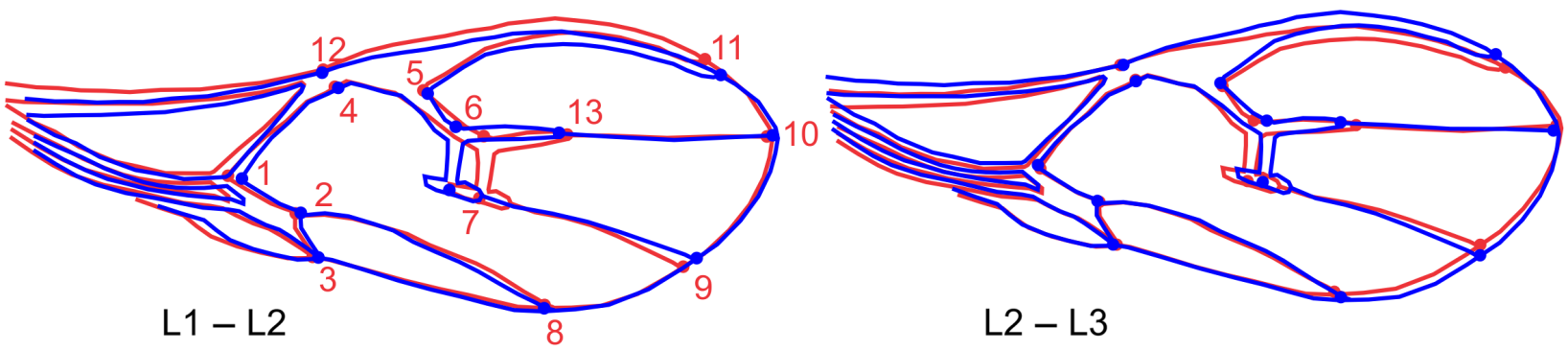

L2 - L3
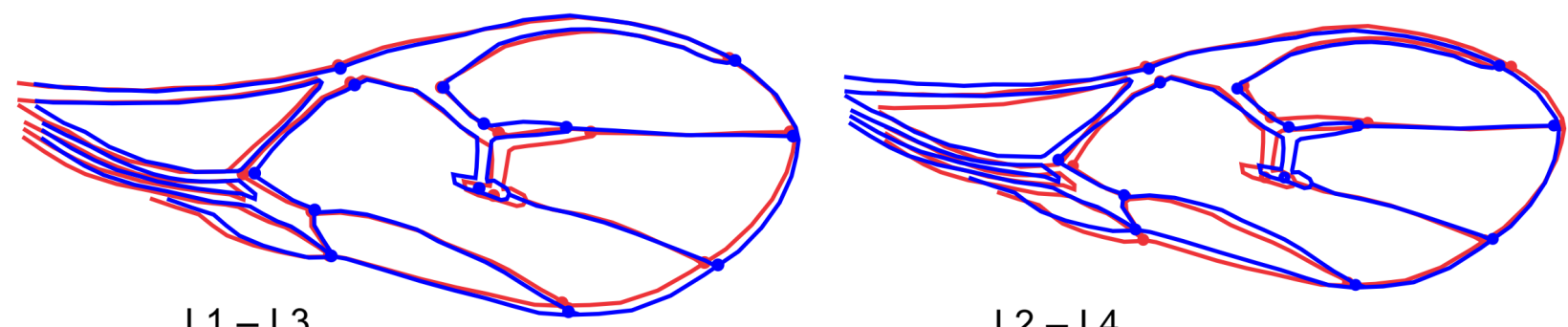

$\mathrm{L} 2-\mathrm{L} 4$
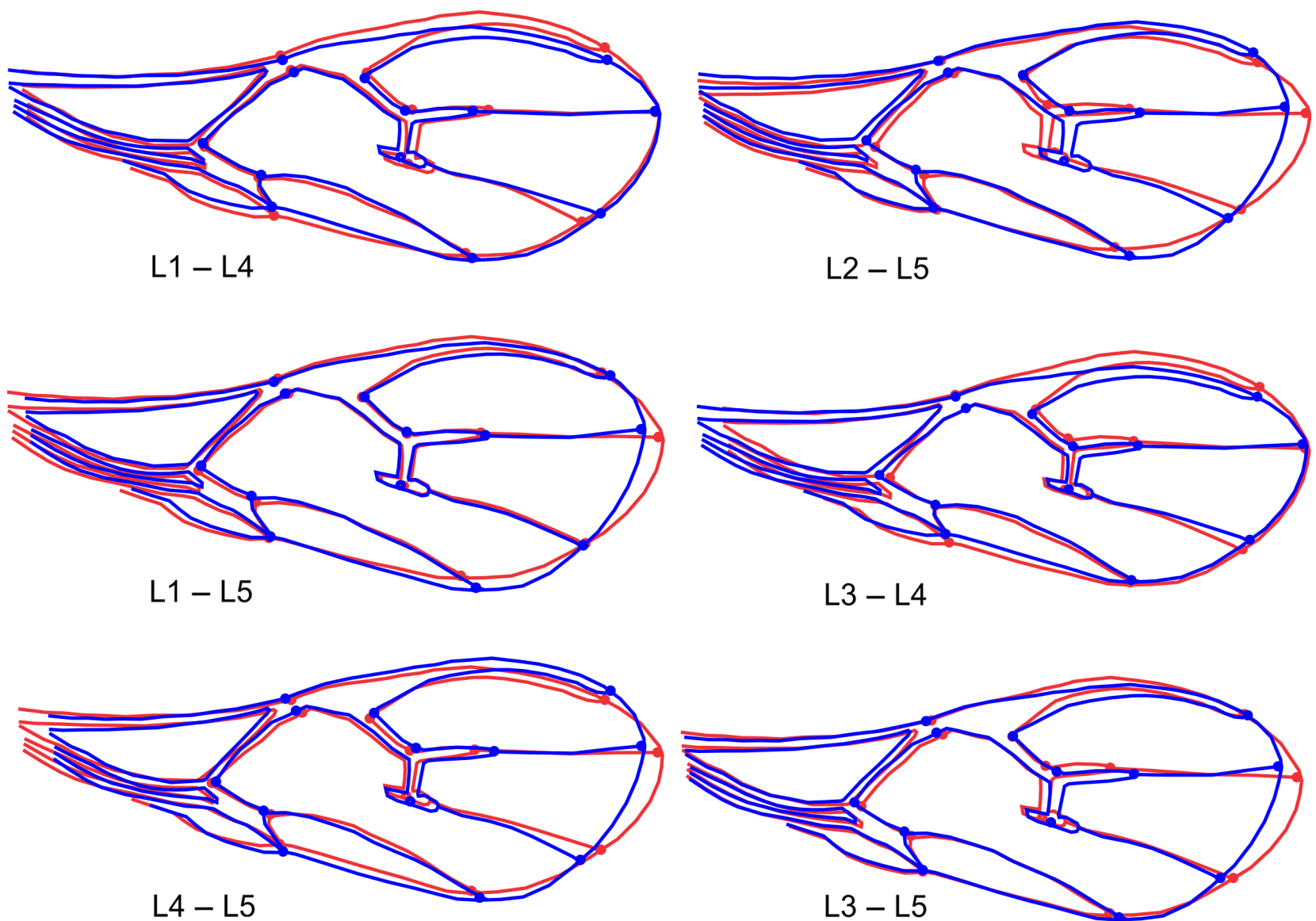

Figure 4. Illustration of wing shape differences amongst the five asexual lines of Lysiphlebus fabarum used in this study. The shape changes are shown as the difference between the average shape of the first group (red) and the average shape of the second group (dark blue). All changes are enlarged two times. 
it is unlikely to be universal. For example, a recent study on bumblebees has shown that wing shape is virtually useless for species delimitations (Lecocq et al., 2015), whereas another study on hornets found wing shape to be a very reliable predictor of species identity (Perrard et al., 2014).

The differences in wing shape amongst lines of $L$. fabarum were mainly related to the width of the wing's distal part, the length of the metacarpus, and the length of the radial vein (Fig. 4). Although these differences could reasonably be related to flight ability, we are not able to conclude whether they are in any way adaptive. Substantial intraspecific variability as observed here does not suggest that wing shape is under strong selection (Mousseau \& Roff, 1987). Parasitoids of the genus Lysiphlebus indeed appear to be more reluctant to fly than other aphid parasitoids (C. Vorburger, pers. observ.), and they are known to be relatively poor dispersers (Rauch \& Weisser, 2007). That said, high intraspecific diversity also implies that wing shape could evolve rapidly if it came under strong natural selection.

To summarize, we quantified the relative importance of parasitoid genotype and aphid host on wing shape variation in asexual lines of the aphid parasitoid L. fabarum. Although the host affected wing shape significantly, it did not do so to the extent that it would obscure the differences amongst genetically distinct lineages. Assuming that this robustness of genetically determined wing shape applies to variation amongst species as well, analysis of this trait is a valuable additional tool in the toolbox of taxonomists studying difficult groups such as parasitoids of aphids, which offer little in terms of directly measurable morphological traits to distinguish taxa.

\section{ACKNOWLEDGEMENTS}

We thank P. Rodriguez for her help with the rearing of aphids and parasitoids, T. Schwander for her input on the experimental design, and the reviewers for helpful comments on the manuscript. This work was supported by a MSc fellowship from the University of Lausanne to M. A. P. and by the Swiss National Science Foundation (SNSF Professorship PP00P3_146341 and Sinergia grant CRSII3_154396 to C. V.). The contributions of Ž. T., V. Ž., and A. P. were partly supported by the Serbian Ministry of Education, Sciences and Technological Development (III43001).

\section{REFERENCES}

Belshaw R, Quicke DLJ. 2003. The cytogenetics of thelytoky in a predominantly asexual parasitoid wasp with covert sex. Genome 46: 170-173.
Belshaw R, Quicke DLJ, Völkl W, Godfray HCJ. 1999. Molecular markers indicate rare sex in a predominantly asexual parasitoid wasp. Evolution 53: 1189-1199.

Birdsall K, Zimmerman E, Teeter K, Gibson G. 2000. Genetic variation for the positioning of wing veins in Drosophila melanogaster. Evolution \& Development 2: 16-24.

Ferrari J, West JA, Via S, Godfray HCJ. 2012. Population genetic structure and secondary symbionts in host-associated populations of the pea aphid complex. Evolution 66: 375-390.

Godfray HCJ. 1994. Parasitoids: behavioral and evolutionary ecology. Princeton: Princeton University Press.

Grant PR, Grant BR. 1995. Predicting microevolutionary responses to directional selection on heritable variation. Evolution 49: 241-251.

Klingenberg CP. 1998. Heterochrony and allometry: the analysis of evolutionary change in ontogeny. Biological Reviews 73: 79-123.

Klingenberg CP. 2011. MorphoJ: an integrated software package for geometric morphometrics. Molecular Ecology Resources 11: 353-357.

Kos K, Trdan S, Petrović A, Starý P, Kavallieratos NG, Petrović-Obradović O, Tomanović Ž . 2012. Aphidiinae (Hymenoptera, Braconidae, Aphidiinae) from Slovenia, with description of a new Aphidius species. Zootaxa 3456: 36-50.

Langerhans RB, DeWitt TJ. 2004. Shared and unique features of evolutionary diversification. American Naturalist 164: 335-349.

Lecocq T, Dellicour S, Michez D, Dehon M, Dewulf A, De Meulemeester T, Brasero N, Valterova I, Rasplus JY, Rasmont P. 2015. Methods for species delimitation in bumblebees (Hymenoptera, Apidae, Bombus): towards an integrative approach. Zoologica Scripta 44: 281-297.

Mitrovski-Bogdanović A, Petrović A, Mitrović M, Ivanović A, Žikić V, Starý P, Vorburger C, Tomanović Z. 2013. Identification of two cryptic species within the Praon abjectum group (Hymenoptera: Braconidae: Aphidiinae) using molecular markers and geometric morphometrics. Annals of the Entomological Society of America 106: 170-180.

Mitrovski-Bogdanović A, Tomanović Ž, Mitrović M, Petrović A, Ivanović A, Žikić V, Starý P, Vorburger C. 2014. The Praon dorsale-yomenae s.str. complex (Hymenoptera, Braconidae, Aphidiinae): species discrimination using geometric morphometrics and molecular markers with description of a new species. Zoologischer Anzeiger 253: 270-282.

Monteiro LR. 1999. Multivariate regression models and geometric morphometrics: the search for causal factors in the analysis of shape. Systematic Biology 48: 192-199.

Moran NA, Russell JA, Koga R, Fukatsu T. 2005. Evolutionary relationships of three new species of Enterobacteriaceae living as symbionts of aphids and other insects. Applied and Environmental Microbiology 71: 3302-3310.

Mousseau TA, Roff DA. 1987. Natural selection and the heritability of fitness components. Heredity 59: 181-197.

Nijhout HF. 1999. Control mechanisms of polyphenic development in insects - In polyphenic development, environmental factors alter same aspects of development in an orderly and predictable way. BioScience 49: 181-192. 
Oliver KM, Russell JA, Moran NA, Hunter MS. 2003. Facultative bacterial symbionts in aphids confer resistance to parasitic wasps. Proceedings of the National Academy of Sciences of the United States of America 100: 1803-1807.

Perrard A, Baylac M, Carpenter JM, Villemant C. 2014. Evolution of wing shape in hornets: why is the wing venation efficient for species identification? Journal of Evolutionary Biology 27: 2665-2675.

Petrović A, Žikić V, Petrović-Obradović O, Bogdanović AM, Kavallieratos NG, Starý P, Tomanović Ž. 2011. Two new species of aphid parasitoids (Hymenoptera, Braconidae, Aphidiinae) from the Balkan Peninsula. Zootaxa 2895: 58-64.

Petrović A, Mitrović M, Ivanović A, Žikić V, Kavallieratos NG, Starý P, Bogdanović AM, Tomanović Ž Vorburger C. 2015. Genetic and morphological variation in sexual and asexual parasitoids of the genus Lysiphlebus - an apparent link between wing shape and reproductive mode. BMC Evolutionary Biology 15: 5.

$\mathbf{R}$ Core Team 2015. $R$ : a language and environment for statistical computing. Vienna, Austria: R Foundation for Statistical Computing. URL http://www.R-project.org.

Rakhshani E, Tomanović Ž, Starý P, Kavallieratos NG, Ilić M, Stanković SS, Rajabi-Mazhar N. 2011. Aphidiinae parasitoids (Hymenoptera: Braconidae) of Macrosiphoniella aphids (Hemiptera: Aphididae) in the western Palaearctic region. Journal of Natural History 45: 2559-2575.

Rauch G, Weisser WW. 2007. Local and spatial dynamics of a host-parasitoid system in a field experiment. Basic and Applied Ecology 8: 89-95.

Rohlf FJ. 2009. TpsDig2 program, version 2.12. Ecology and Evolution, SUNY at Stony Brook, State University of New York (available at: http://life.bio.sunysb.edu/morph/).

Rouchet R, Vorburger C. 2012. Strong specificity in the interaction between parasitoids and symbiont-protected hosts. Journal of Evolutionary Biology 25: 2369-2375.

Sandrock C, Vorburger C. 2011. Single-locus recessive inheritance of asexual reproduction in a parasitoid wasp. Current Biology 21: 433-437.

Sandrock C, Frauenfelder N, Von Burg S, Vorburger C. 2007. Microsatellite DNA markers for the aphid parasitoid Lysiphlebus fabarum and their applicability to related species. Molecular Ecology Notes 7: 1080-1083.

Sandrock C, Schirrmeister BE, Vorburger C. 2011. Evolution of reproductive mode variation and host associations in a sexual-asexual complex of aphid parasitoids. BMC Evolutionary Biology 11: 348.

Sharkey MJ, Wharton RA. 1997. Morphology and terminology. In: Wharton RA, Marsh PM, Sharkey MJ, eds. Manual of the new world genera of the family Braconidae
(Hymenoptera). Washington, DC: International Society of Hymenopterists, 19-37.

Smith MA, Woodley NE, Janzen DH, Hallwachs W, Hebert PDN. 2006. DNA barcodes reveal cryptic host-specificity within the presumed polyphagous members of a genus of parasitoid flies (Diptera: Tachinidae). Proceedings of the National Academy of Sciences of the United States of America 103: 3657-3662.

Smith MA, Wood DM, Janzen DH, Hallwachs W, Hebert PDN. 2007. DNA barcodes affirm that 16 species of apparently generalist tropical parasitoid flies (Diptera, Tachinidae) are not all generalists. Proceedings of the National Academy of Sciences of the United States of America 104: 4967-4972.

Smith MA, Rodriguez JJ, Whitfield JB, Deans AR, Janzen DH, Hallwachs W, Hebert PDN. 2008. Extreme diversity of tropical parasitoid wasps exposed by iterative integration of natural history, DNA barcoding, morphology, and collections. Proceedings of the National Academy of Sciences of the United States of America 105: 12359-12364.

Stanković SS, Petrović A, Ilić Milosević M, Starý P, Kavallieratos NG, Žikić V, Tomanović Ž. 2015. Morphological and molecular characterization of common European species of Adialytus (Hymenoptera: Braconidae: Aphidiinae) based on the mtCOI barcoding gene and geometric morphometrics of forewings. European Journal of Entomology 112: 165-174.

Starý P. 1970. Biology of aphid parasites (Hymenoptera: Aphidiidae) with respect to integrated control. The Hague: Dr. W. Junk N. V. Publishers.

Starý P. 1988. Aphidiidae. In: Minks AK, Harrewijn P, eds. Aphids: their biology, natural enemies, and control, Vol. 2B. Amsterdam: Elsevier, 171-184.

Starý P. 2006. Aphid parasitoids of the Czech Republic (Hymenoptera: Braconidae, Aphidiinae). Praha: Academia.

Swan DC. 1936. Berlese's fluid: remarks upon its preparation and use as a mounting medium. Bulletin of Entomological Research 27: 389-391.

Tremblay E, Eady RD. 1978. Lysiphlebus confusus, new name for Lysiphlebus ambiguus (Hymenoptera, Ichneumonidae). Bollettino del Laboratorio di Entomologia Agraria Filippo Silvestri 35: 180-184.

Vorburger C, Sandrock C, Gouskov A, Castañeda LE, Ferrari J. 2009. Genotypic variation and the role of defensive endosymbionts in an all-parthenogenetic host-parasitoid interaction. Evolution 63: 1439-1450.

Žikić V, Tomanović Ž, Ivanović A, Kavallieratos NG, Starý P, Stanisavljević LZ, Rakhshani E. 2009. Morphological characterization of Ephedrus persicae biotypes (Hymenoptera: Braconidae: Aphidiinae) in the Palaearctic. Annals of the Entomological Society of America 102: 1-11.

\section{SUPPORTING INFORMATION}

Additional supporting information may be found online in the supporting information tab for this article:

Table S1. Pairwise differences in wing shape between five asexual lines of Lysiphlebus fabarum that developed in four different aphid host species. 